\title{
Analysis of Outpatient Trauma Referrals in a Sub-Saharan African Orthopedic Center
}

\author{
Harry Jergesen • David Oloruntoba • \\ Edward Aluede $\cdot$ Monica Grova • \\ Jonathan Phillips $\cdot$ Amber Caldwell
}

Published online: 1 March 2011

(C) The Author(s) 2011. This article is published with open access at Springerlink.com

\begin{abstract}
Background The purpose of this study was to characterize the orthopedic trauma workload in the Bedford Orthopaedic Centre (BOC), an orthopedic referral hospital in rural South Africa.

Methods Demographic data, injury data, and information about initial management were collected for two 6-week periods during both 2008 and 2009 from patients seen in the BOC outpatient department. Two primary outcomes were evaluated: (1) the interval between the initial outside evaluation and the BOC consultation and (2) the presence of established infection at the time of consultation. Secondary outcomes included assessments of the initial management at the referring facility.

Results Most patients were adult men. Almost half were referred from within a radius of $10 \mathrm{~km}$, but more than onethird came from facilities in excess of $50 \mathrm{~km}$ away. The most frequent mode of transport was ambulance followed by taxi-van. Fractures accounted for most of the injuries. Motor vehicle accidents and assaults were more prevalent among adults than among children, for whom falls accounted for a large proportion of injuries. Referral was delayed more than $72 \mathrm{~h}$ in $41.4 \%$ of patients. Established
\end{abstract}

\footnotetext{
H. Jergesen $(\bowtie) \cdot$ E. Aluede · M. Grova · J. Phillips ·

A. Caldwell

Institute for Global Orthopaedics and Traumatology, Department of Orthopedic Surgery, San Francisco General Hospital, 2550 23rd Street, Building 9, 2nd Floor, San Francisco, CA 94110, USA

e-mail: jergesen@orthosurg.ucsf.edu

D. Oloruntoba

Bedford Orthopaedic Centre, Private Bag X5103, Mthatha 5100, Republic of South Africa
}

infections were indentified in $12.2 \%$. Deficiencies detected during prehospital care were common.

Conclusion The burden of orthopedic trauma in this rural referral center is sufficient to justify the manpower and resources needed for a major orthopedic trauma center. Because most of the injuries were fractures, efforts should be aimed at improving fracture care. Differences in the mode of injury and in the anatomical sites involved between adults and children highlight the need for focused preventive measures. Reducing both delays in referral and deficiencies in initial management might well reduce the cost and complexity of the definitive treatment required.

\section{Introduction}

Increasing attention is being paid worldwide to the public health implications of musculoskeletal injuries and trauma, especially in the developing world. The impact of these injuries is especially severe in those countries where human and material resources are most limited. Data concerning the disease burden is such settings are lacking [1]. The eastern portion of the Eastern Cape Province in South Africa (formerly the Transkei homeland) contains a largely indigent, rural population of three to four million people. The role of injury and violence as a leading cause of death in this region has been well documented by Meel [2-6]. The Eastern Cape Province Department of Health administers a network of clinics and district hospitals that provide care to this population. The Mthatha Hospital Complex in Mthatha provides referral care for this portion of the province as well as primary care for the population in the greater Mthatha area. In recent years, the area around the hospital has experienced an increase in population and a corresponding increase in trauma due to falls, violence, 
and road traffic accidents. The 180-bed Bedford Orthopaedic Centre (BOC), located $8 \mathrm{~km}$ outside of the city, provides the orthopedic care for the Complex. Thus, referrals to the BOC come both from within the Mthatha Hospital Complex and from district hospitals staffed by general medical officers with little or no orthopedic training. The BOC is the primary location where care is given to patients with both orthopedic injuries and musculoskeletal conditions such as tuberculosis, tumors, and arthritis.

Previous studies

Past efforts to assess the workload at the BOC focused on assessing the number of admissions and outpatient visits. Unpublished data from 1997 through April 2007 ${ }^{1}$ indicate that the number of yearly admissions to BOC nearly doubled during this period. Nonetheless, the bed capacity remained stable at 180 beds and the staffing unchanged, resulting in an increased workload and an increased demand on already limited resources and facilities. Paralleling the increase in admissions, there was an approximately $28 \%$ increase in the number of patients seen in the outpatient department (OPD) - to more than 18,000 visits per year estimated for 2007. In a report on admissions to the male ward at the BOC during a 4-month period in 2005, Millar and MacConnachie documented a large trauma workload, the prominent role of motor vehicle accidents (MVAs) as a cause of injury, and the frequency of delays in treatment [7]. At present, hospital admissions for patients in the OPD often are delayed owing to the limited number of open beds, with priority given to patients with the most urgent needs. Beds frequently are in short supply because hospitalized patients must wait days or weeks for surgery due to the lack of surgical theater time. It is not uncommon for admissions from the OPD to be deferred more than once for a given patient.

Purpose of the current study

ncreases in the number of patients seen at this facility have been well documented. However, inadequate prehospital care, delays in referral, and delays in admission may increase the complexity of treatment ultimately undertaken, in turn resulting in increased utilization of personnel and resources. This study is designed to document the demographic characteristics of all trauma patients being treated, the nature of their injuries, and subjective assessment of initial prehospital care given at the referring site. The primary outcomes assessed were (1) a delay of more than $72 \mathrm{~h}$ between the initial evaluation and the BOC consultation and (2) the presence of infection at the time of the BOC consultation. Both of these outcomes were thought to reflect potentially

$\overline{1}$ Oliver-Allen, Hunter, unpublished data, 2007 modifiable factors that add to the complexity of care and thus to the burden of disease encountered.

\section{Methods}

Institutional review board (IRB) approval for the study was obtained from the University of California, San Francisco Committee on Human Research and from the Medical Ethics Committee of the Walter Sisulu University Faculty of Medical Sciences. Data were collected at the BOC during two 6-week periods during July and August of 2008 and 2009. These periods represented average periods of trauma volume at the BOC.

Medical student researchers collected the data from patients in the BOC outpatient department and from the orthopedic medical officers treating them. When necessary, the patient interviews were facilitated by Xhosa-speaking interpreters. Information from data collection sheets was transferred to spreadsheets, and descriptive statistics were derived from these data.

The two primary outcomes-delay in referral of more than $72 \mathrm{~h}$ following evaluation at the initial facility and the presence of infection at the time of consultation-were evaluated with respect to demographic and injury data. The statistical significance of the association between each outcome and each variable was evaluated with chi-square tests, using, where appropriate, Fisher's exact test and Pearson's test.

Secondary outcomes that were evaluated were derived from the subjective assessment by the BOC medical staff of specific aspects of the initial care provided prior to BOC consultation. BOC physicians were queried about correctness of the initial diagnosis, the presence of radiographs adequate to determine diagnosis and treatment, adequacy of initial wound management, proper splint immobilization, and a general assessment of the initial management as adequate or inadequate. Finally, treating physicians at BOC were queried as to whether they thought the orthopedic injuries that were being assessed might have been adequately managed at the initial hospital without referral if instruction in the management of simple orthopedic problems had been available. The same demographic and injury variables described previously were statistically evaluated to assess possible relations to these secondary outcomes.

\section{Results}

General demographics

Demographic data from the 1055 patients seen in the BOC outpatient department during the 6-week periods in 2008 
and in 2009 are presented in Tables 1, 2, 3, 4, and 5 . Altogether, $80 \%$ of the patients treated were adults (defined in this setting as individuals $>14$ years of age). Most of the patients seen in both the adult and pediatric groups were male (Table 1). In addition, $56 \%$ of the adult patients reported that they were responsible for caring for dependents, either children or elderly relatives.

In all, $48.6 \%$ of patients were referred from facilities in Mthatha, $<10 \mathrm{~km}$ away, with most from the academic hospital and from the city's general hospital; $38.6 \%$ of patients came from district hospitals $>50 \mathrm{~km}$ from the BOC; and $12.7 \%$ were from hospitals $11-50 \mathrm{~km}$ away. The primary mode of transportation was ambulance for twothirds of patients, with about one-fourth arriving by taxivan, the primary mode of public transportation in the Eastern Cape (Table 2). There was no significant difference in the type of transportation used by the adult and pediatric populations.

Characteristics of the injuries evaluated are listed in Table 3. Most were fractures, with a somewhat higher prevalence in the pediatric group. Soft tissue injuries occurred with greater frequency in adults $(13.9 \%)$ than in children $(7.1 \%)$. Information about whether the presenting injuries were open or closed was not collected during the 2008 session but was collected in 2009. Among the 521 patients evaluated in 2009, injuries were open in 89 $(17.1 \%)$, with a more than twofold greater prevalence in adults than in children and almost a twofold greater prevalence in males than in females.

Most of the injuries seen (51.5\%) involved the lower extremity, with a greater prevalence of these injuries in adults and females (Table 4). The greater prevalence of

Table 1 Age and sex data of trauma patients $(n=1040)$

\begin{tabular}{llll}
\hline Parameter & $\begin{array}{l}\text { Adults } \\
(\text { age }>14 \text { years })\end{array}$ & $\begin{array}{l}\text { Pediatric group } \\
(\text { age } \leq 14 \text { years })\end{array}$ & $\begin{array}{l}\text { All } \\
\text { patients }\end{array}$ \\
\hline $\begin{array}{c}\text { Age (years), } \\
\text { mean }\end{array}$ & $40.0(n=830)$ & $8.5(n=210)$ & 33.6 \\
$\begin{array}{l}\text { Sex (no.) } \\
\text { Male }\end{array}$ & $500(60.2 \%)$ & $149(71.0 \%)$ & $649(62.6 \%)$ \\
Female & $330(39.8 \%)$ & $61(29.0 \%)$ & $391(37.4 \%)$ \\
\hline
\end{tabular}

Table 2 Mode of transportation to Bedford Orthopaedic Centre from referring facility

\begin{tabular}{lclc}
\hline Mode & Adults (\%) & $\begin{array}{l}\text { Pediatric } \\
\text { group (\%) }\end{array}$ & All patients (\%) \\
\hline Taxi & 24.7 & 21.0 & 24.3 \\
Ambulance & 66.0 & 71.0 & 66.7 \\
Walk & 0.2 & 0.5 & 0.3 \\
Private car & 8.2 & 2.4 & 6.9 \\
Unknown/other & 1.0 & 5.2 & 1.8 \\
\hline
\end{tabular}

Table 3 Type of presenting orthopedic injury

\begin{tabular}{lccc}
\hline Injury & Adults (\%) & $\begin{array}{l}\text { Pediatric } \\
\text { group }(\%)\end{array}$ & $\begin{array}{l}\text { All patients } \\
(\%)\end{array}$ \\
\hline Fracture & 79.6 & 87.1 & 80.9 \\
Dislocation & 3.4 & 1.9 & 3.0 \\
Soft tissue & 13.9 & 7.1 & 12.8 \\
Other & 3.1 & 3.8 & 3.2 \\
Open injury (2009 only) & 19.2 & 8.0 & 17.1 \\
\hline
\end{tabular}

Table 4 Site of injury

\begin{tabular}{lcll}
\hline Site & Adults (\%) & $\begin{array}{l}\text { Pediatric } \\
\text { group }(\%)\end{array}$ & $\begin{array}{l}\text { All patients } \\
(\%)\end{array}$ \\
\hline Upper extremity & 38.4 & 54.8 & 41.7 \\
Lower extremity & 55.8 & 40.5 & 52.7 \\
Multiple sites & 1.9 & 4.3 & 2.5 \\
Spine/head & 3.7 & 0.5 & 3.0 \\
Unknown & 0.1 & 0 & 0.1 \\
\hline
\end{tabular}

upper extremity injuries in the pediatric group likely reflects the frequency of supracondylar humerus fractures due to falls. Accidents involving motor vehicles accounted for $22.9 \%$ of the injuries seen in all patients and were more prevalent in adults (Table 5). Injuries resulting from assaults were far more common in adults $(18.2 \%)$ than in children $(0.5 \%)$. Other injuries, usually falls, accounted for a larger proportion of injuries encountered in children $(83.3 \%)$ than in adults $(56.4 \%)$.

Only a small portion of the patients seen at BOC for orthopedic trauma were aware of their human immunodeficiency virus (HIV) status and if they were actively infected with tuberculosis (TB). Patients were not routinely screened for HIV. A total of $11.8 \%$ of all patients reported having HIV/acquired immunodeficiency syndrome (AIDS) at the time they were evaluated: $13.7 \%$ of the adults and $4.3 \%$ of the children. In all, $7.5 \%$ of patients had known TB: $9.2 \%$ of adults and $1.0 \%$ of children.

Altogether, $19.5 \%$ of the patients were referred from five district hospitals, the staffs of which attended a course on the care of orthopedic trauma during the months that separated the data collection periods of 2008 and 2009. In all, 99 patients referred from these hospitals were evaluated in 2008 (prior to the introduction of the course), and 107 were evaluated in 2009 (after the course was given).

\section{Outcomes assessment}

\section{Primary outcomes}

Primary outcomes assessed as part of this study include both delay in referral and the presence of infection at the 
Table 5 Mechanism of injury

\begin{tabular}{lccl}
\hline Mechanism & Adults (\%) & $\begin{array}{l}\text { Pediatric } \\
\text { group }(\%)\end{array}$ & $\begin{array}{l}\text { All patients } \\
(\%)\end{array}$ \\
\hline MVA-related & 24.7 & 14.8 & 22.9 \\
Assault & 18.2 & 0.5 & 14.4 \\
Other (e.g., falls) & 56.4 & 83.3 & 61.8 \\
Unknown & 0.7 & 1.4 & 0.9 \\
\hline
\end{tabular}

MVA motor vehicle accident

initial BOC consultation. The interval between the initial evaluation at the referring facility and the initial evaluation at BOC was recorded for all 1055 patients. Information on the presence of infection at the time of consultation was reported for 650 of the 1055 patients during the two data collection periods. Univariate analysis with chi-square tests determined which demographic factors and injury data appeared to be related to each of these primary outcomes.

Patients who were divided into two groups depending on whether the BOC visit had occurred within $72 \mathrm{~h}$ of the initial visit or was delayed more than $72 \mathrm{~h}$ (Table 6). Factors that correlated statistically with the delayed referral included mode of transportation and distance from the referral site (Table 7). Also found to be related were whether the patients were seen in 2008 or 2009 and

Table 6 Interval between initial evaluation and Bedford Orthopaedic Center visit

\begin{tabular}{llll}
\hline Interval & Adults (\%) & $\begin{array}{l}\text { Pediatric } \\
\text { group }(\%)\end{array}$ & $\begin{array}{l}\text { All patients } \\
(\%)\end{array}$ \\
\hline$\leq 72 \mathrm{~h}$ & 58.1 & 60.5 & 58.6 \\
$>72 \mathrm{~h}$ & 41.9 & 39.5 & 41.4 \\
\hline
\end{tabular}

whether they were seen in a hospital where the trauma course was given. Of importance is the fact that the ambulance service improved between 2008 and 2009 . Factors that did not appear to be related to delayed referral included age, sex, site of injury, type of injury, open versus closed injury, presence of infection, and whether HIV/ AIDS or TB were known to be present.

A total of $12.2 \%$ of these patients were reported to have an established infection at the time of the initial evaluation at BOC. Infections were noted in $11.4 \%$ of patients in the pediatric group and in $16.4 \%$ of adults (Table 7 ); $15.2 \%$ of males and $8.4 \%$ of females were diagnosed with infections. Factors associated with the presence of infection included sex, mechanism and type of injury, and whether the injury was open or closed. Factors not associated included age, distance from referral site, mode of transportation, delayed referral of $>72 \mathrm{~h}$, and site of injury. Other factors not related were whether the patients were seen in 2008 or 2009 , whether they were seen in hospitals where the trauma course was given, and whether TB or HIV/AIDS were known to be present.

\section{Secondary outcomes}

The orthopedic medical officers at the BOC judged that the initial care provided at the referring facility in some way was deficient for $36 \%$ of the patients: $17 \%$ of the patients were thought to have received an incorrect diagnoses at the initial examination site; $11 \%$ had inadequate radiographs; and $19 \%$ of fractures were judged to have inadequate splint immobilization. Finally, it was estimated that $27 \%$ of the referred patients might have been managed without referral at the district hospital if the referring staff had had proper basic instruction in orthopedic care. In fact, data collected from patients referred from the five district hospitals where
Table 7 Statistical association between primary outcomes and selected variables

BOC Bedford Orthopaedic Center, HIV/AIDS human immunodeficiency virus/ acquired immunodeficiency syndrome, $T B$ tuberculosis, $N S$ not significant, Sig significant, N/A not applicable

a Fischer's exact test

${ }^{\mathrm{b}}$ Pearson chi-square test

\begin{tabular}{lll}
\hline Demographic data & Delay in referral $\geq 72 \mathrm{~h}$ & Presence of infection \\
\hline Age & NS $(0.583)^{\mathrm{a}}$ & NS $(0.323)^{\mathrm{a}}$ \\
Sex & NS $(0.898)^{\mathrm{a}}$ & Sig. $(0.011)^{\mathrm{a}}$ \\
Distance between BOC and referring facility & Sig. $(0.002)^{\mathrm{b}}$ & NS $(0.579)^{\mathrm{b}}$ \\
Mode of transportation & Sig. $(0.033)^{\mathrm{b}}$ & NS $(0.839)^{\mathrm{b}}$ \\
Data from 2008 or 2009 & Sig. $(0.000)^{\mathrm{a}}$ & NS $(0.802)^{\mathrm{a}}$ \\
Presence of HIV/AIDS, TB & NS $(0.388)^{\mathrm{a}}$ & NS $(0.243)^{\mathrm{b}}$ \\
Referred from hospital with trauma training & Sig. $(0.024)^{\mathrm{a}}$ & NS $(1.000)^{\mathrm{a}}$ \\
Delay in referral & N/A & NS $(0.713)^{\mathrm{a}}$ \\
Type of injury & NS $(0.124)^{\mathrm{b}}$ & Sig. $(0.000)^{\mathrm{b}}$ \\
Mechanism of injury & Sig $(0.020)^{\mathrm{b}}$ & Sig $(0.014)^{\mathrm{b}}$ \\
Site of injury & NS $(0.920)^{\mathrm{b}}$ & NS $(0.402)^{\mathrm{b}}$ \\
Open vs. closed (2009 only) & NS $(0.690)^{\mathrm{a}}$ & Sig. $(0.000)^{\mathrm{a}}$ \\
Presence of infection & NS $(0.713)^{\mathrm{a}}$ & N/A \\
\hline
\end{tabular}


the staff had been given proper trauma instruction showed that after the course was given to the staff there was no difference in the prevalence of perceived deficiencies in the initial care.

\section{Discussion}

This study confirms the clinical impression that the burden of orthopedic trauma addressed in the BOC outpatient department is substantial and, furthermore, that fractures are the most frequently diagnosed injuries. A logical first step in managing a heavy trauma workload in resourceconstrained settings is to document the number of patients and the types of injury being seen. Such information is essential for governmental agencies to identify where the greatest health care needs lie and to prioritize scarce resources. To offer adequate treatment to large numbers of patients with fractures and related injuries, resources commensurate with the workload are required, as recommended by the World Health Organization (WHO) in Guidelines for Essential Trauma Care [8, 9]. Such resources include emergency transportation, adequately trained first responders, and properly equipped outpatient and inpatient facilities. Because surgical treatment is the standard of care for most of these injuries, also needed are adequate operative facilities, staffing, supplies, equipment, and orthopedic implants [10]. Data from this study provide a starting point for applying resources effectively.

It is well understood that delays in definitive treatment of fractures may result in the need for more complex treatment and to poor outcomes. A prior study at the BOC revealed that treatment delays of $>7$ days occurred in $25 \%$ of male inpatients [7]. In the present study, delayed referral of $>72 \mathrm{~h}$ was noted in $41.4 \%$ of all trauma patients seen in the outpatient department. Analysis of factors possibly associated with such delays showed a statistical relation to the distance traveled to the BOC, the type of transportation used, and the year in which data were gathered. The reduced prevalence of referral delays between 2008 and 2009 may be explained in large part by the improvements in the ambulance services that were instituted between these data collection periods. The use of crowded and dangerous taxi-vans, which is the only other alternative for most indigent patients, is particularly cumbersome and expensive when traveling long distances to the BOC. The findings in this study highlight the importance of creating and maintaining adequate transport systems for injured patients, especially for those living in distant communities.

A total of $12.2 \%$ of patients seen in the BOC OPD were diagnosed as having established infections. The infections were more common in adult men and, not surprisingly, were significantly associated with open injuries. Treatment of infected, open injuries frequently requires more intensive management with prolonged inpatient hospital stays, multiple surgical procedures, and prolonged intravenous antibiotic treatment. The reported incidence of infection following open fractures in developed countries, where various standard care protocols are used, is in the range of $2.3 \%$ to $7.3 \%[11,12]$. To minimize the risk of infection in the setting of rural South Africa, it is important to institute measures that promote adequate débridement of open fractures and prompt administration of intravenous antibiotics during the initial treatment at the district hospitals.

This present study documents the prevalence of perceived deficiencies in initial care at the district hospitals from which BOC patients were referred. It is recognized that such perceived deficiencies may have multiple causes and that their recognition may have been affected by the bias of caregivers at the BOC. However, it is noteworthy that these observations were made by local practitioners within the context of established standards of orthopedic care in this setting.

Injuries that are not properly managed at the outset may require more complex, time-consuming, and costly definitive care later. With the goal of reducing the prevalence of problems - such as missed diagnoses, inadequate radiographic studies, missed neurovascular injuries, inadequately managed open injuries - a course on the care of acute orthopedic injuries was given at 5 of the 23 district hospitals between the 2008 and 2009 data collection periods. The goal of this instruction was similar to that advocated in the WHO's Integrated Management for Emergency and Essential Surgical Care (IMEESC) program [9, 13]. Of interest is the finding of the present study that referral delays in 2009 were reduced following the course. Improvements in ambulance transportation, as well as the information imparted during the courses in these hospitals, may explain why referral delays were less frequent during the second data collection period. Of note, however, is the fact that the prevalence of reported deficiencies in initial care of patients referred from those hospitals did not decrease where the courses were given. A possible explanation for this finding may be that many of the medical officers who had received the instruction at the district hospitals had moved away from the subject hospitals during the months after the courses were given. Thus, many of the patients seen during the second data collection period may not have been treated by physicians who had undergone the trauma training. This underscores the challenges in creating sustainable and measurable changes in clinical practice using educational interventions of the type described.

What are the next steps? Continuing educational efforts at the district hospital level is important, but such efforts must be ongoing and targeted especially to newly arrived 
physicians. Now that the workload has been documented at the BOC, an important challenge lies in improving orthopedic care in the hospital, especially surgical intervention. Measuring the efficiency with which patients are managed at the BOC itself may provide further insight into whether available resources are adequate and are being properly utilized. As alluded to previously, problems caused by delays in referral are compounded by delays in getting patients admitted to the BOC and by further delays in getting inpatients to surgery in a timely fashion. The next challenge at the BOC is to gather data on the number of patients whose treatment is delayed due to lack of hospital beds and the number of hospitalized patients who experience delays in getting to theater for their needed surgery. Data on the causes of delay in the surgical theaters are of importance. Are there sufficient theaters? Is the nursing staffing adequate? Are there sufficient anesthetists and surgeons? Are there sufficient supplies, equipment, and surgical implants? Further data collection aimed at answering these questions is needed to focus interventions designed to improve both the prehospital care and definitive management of patients with orthopedic trauma in this region.

Acknowledgments This study was supported by grants from the Institute for Global Orthopaedics and Traumatology and the Office of the Dean, University of California, San Francisco.

Conflict of interest The authors report no potential or real conflicts of interest.

Open Access This article is distributed under the terms of the Creative Commons Attribution Noncommercial License which permits any noncommercial use, distribution, and reproduction in any medium, provided the original author(s) and source are credited.

\section{References}

1. Spiegel D, Gosselin R, Coughlin R et al (2008) Topics in global public health. Clin Orthop Rel Res 466:2377-2384

2. Meel BL (2004) Incidence and patterns of violent and/or traumatic deaths between 1993 and 1999 in the Transkei region of South Africa. J Trauma 57:125-129

3. Meel BL (2003) Mortality of children in the Transkei Region of South Africa. Am J Forensic Med Pathol 24:141-147

4. Meel BL (2007) Trends in firearm-related deaths in the Transkei region of South Africa. Am J Forensic Med Pathol 28:86-90

5. Meel BL (2004) Pre-hospital and hospital traumatic deaths in the former homeland of Transkei, South Africa. J Clin Forensic Med 11:6-11

6. Meel BL (2007) Trends in fatal motor vehicle accidents in Transkei region of South Africa. Med Sci Law 47:64-68

7. Millar TMS, McConnachie CCP (2007) Orthopaedic trauma workload in the former homeland of the Transkei, South Africa. Injury 38:147-149

8. Mock C, Cherian M (2008) The global burden of musculoskeletal injuries. Clin Orthop Rel Res 466:2306-2316

9. Surgical Care at the District Hospital, World Health Organization (2003) http://www.who.int/surgery/publications/en/SCDH.pdf

10. Oloruntoba D, Dormans J (2003) Orthopaedics in the developing world: present and future concerns. J Am Acad Orthop Surg 11:75-76

11. Ostermann P, Henry S, Seligson D (1993) The role of local antibiotic therapy in the management of compound fractures. Clin Orthop Rel Res 205:102-111

12. Patzakis M, Dorr L, Ivler D et al (1975) The early management of open fractures: a prospective study of one hundred and forty patients. J Bone Joint Surg Am 57:1065-1070

13. Quanash R, Abantanga F, Donkor P (2008) Trauma training for nonorthopaedic doctors in low- and middle-income countries. Clin Orthop Rel Res 466:2403-2412 